\begin{abstract}
Alejandro Aguilar Zeleny
Poeta, filósofo y antropólogo. Por más de treinta años ha trabajado con los pueblos originarios del noroeste. Ha sido Jefe de la Unión Regional Sonora de Culturas Populares y Director del INAH en Sonora. Actualmente es profesor e investigador del INAH en Sonora, especializado en antropología simbólica y de la ritualidad. Es coautor junto con José Luis Moctezuma Zamarrón de la obra: Pueblos indígenas del noroeste. Atlas Etnográfico, publicado por el INAH, ISC e IHALI en 20 I 5 . Ha montado diferentes exposiciones fotográficas y de carácter etnográfico. Ha realizado los documentos Días y Flores y Para nacer he nacido. Participó en los documentales Sonora a través del tiempo (México Nuevo Siglo), Pueblos en Riesgo (CDI/COLEF/INALI), Hecho en México y Viva Kino. Ha publicado diversa obra poética, fotografía y antropología, entre sus libros se encuentran: Relatos para Arqueólogos y Otros Nostálgicos, Andancias, Noticia de un Viaje al País de los Pimas y La ramada de Babel. Poesía en lenguas I 98 5-20 I 8, publicado por Ediciones Casa del Viento en 20 I 9, Año Internacional de las Lenguas Indígenas, UNESCO, del cual se extrae el siguiente poema traducido al qmique itoom (lengua comcaac) por Arturo Morales Blanco.
\end{abstract}

Protrepsis, Año 9, Número 17 (noviembre 2019 - abril 2020). www.protrepsis.cucsh.udg.mx 


\section{Hihacatol cöicoos}

Coiihazaxohac hant quiniij ziix quisax zitiimic tintica saac quitoj xa quiten hac cohisahotijaha

Hant quinij ziix quisax zitimic tintica tocoitacatax cohasol taax hisoj hisahaha

Tocohicatax coiihico ihat quitax quipxa hocosihaha cosihaptxcohi

Hansopopaspojta hiicaton quic'quishahacoha haha hant quiniij zixx quisax ziitimic tintica coisazaxhac taxocoiquehac zaa quitazo quiticoyticpan quicohamit cac'osxajihhahisax quic'hihaha caosxajhaa

Xepe com coipahahac cosiipihac hiihizaat haay cohiit

miizjpata mosipiha

Haantima ziiquicoispacahax

quimoz coisoitac ziixquicamoquepe xaha xiicaquiquistox qui hicp cohiqui'coiptxaha hantquiniijz ziix quisax ziitimic tintica coipaspojac sehecoimpaha $\mathbf{P}$

\section{Canto ceremonial del desierto}

Digamos

que para hablarte del desierto

necesitaría tener los ojos

la boca

tan secos

como un suspiro de arena

Digamos que hablarte del desierto

sería ponerme amarillo

luminoso extremo

granulado

Sería espinarte un poco

a flor de choyal

sólo por la precisión descriptiva

Hablarte del desierto

es decirte jornadas largas

muy largas

y el ansia de ver el mar

o una sombra fresca

O simplemente el ansia

de mandarse a otra parte

para recordar con nostalgia

el desierto indescriptible

Haxa tipee. $\mathbf{P}$ 